\title{
O uso da música como recurso terapêutico em saúde mental
}

\section{Music as a therapeutic resource in mental health intervention}

\author{
Nayara da Silva Batista ${ }^{1}$, Mara Cristina Ribeiro ${ }^{2}$
}

http://dx.doi.org/10.11606/issn.2238-6149.v27i3p336-341

Batista NS, Ribeiro MC. O uso da música como recurso terapêutico em saúde mental. Rev Ter Ocup Univ São Paulo. 2016 set.-dez.;27(3):336-41.

RESUMO: A partir do acompanhamento de um grupo de música em um Centro de Atenção Psicossocial para Álcool e Drogas foi desenvolvido um estudo com os usuários participantes com objetivo de compreender o papel da música em suas vidas e no tratamento e, com base nos resultados, refletir sobre o uso da música como recurso terapêutico. Trata-se de investigação qualitativa de caráter analítico/descritivo. Utilizou-se de estudo bibliográfico, observação e entrevistas submetidas à análise de conteúdo. Nos resultados, dois principais temas emergiram: Os Impactos da Música e A Potencialidade Terapêutica da Música. Os impactos podem ser positivos, quando associados ao bemestar, recordações e melhora das relações sociais, ou negativos, de acordo com as preferências musicais ou mensagens contidas que podem ser associadas à interferências no tratamento. Com relação à potencialidade terapêutica, verificou-se que a música colabora na constituição de vínculos e no desenvolvimento de mudanças pessoais e coletivas. Conclui-se que a música promove a expressão de emoções e percepção da realidade e a sua utilização no contexto terapêutico favorece o equilíbrio interno e facilita espaços de trocas.

DESCRITORES: Música; Saúde Mental; Serviços de Saúde Mental; Usuários de Drogas.
Batista NS, Ribeiro MC. Music as a therapeutic resource in mental health intervention. Rev Ter Ocup Univ São Paulo. 2016 Sept.-Dec.;27(3):336-41.

ABSTRACT: From the follow-up of a music group in a Psychosocial Care Center for Alcohol and Drugs, a study with drug users was developed to understand the role of music in their lives and in the treatment and, based on the results, to think the use of music as a therapeutic resource. This is a qualitative research with analytical/descriptive characteristics. Bibliographic analysis, observations and interviews were submitted for content analysis. From the results, two main topics emerged: Impacts of Music and Therapeutic Potential of Music. Impacts can be positive, when resulting in well-being, memories of good times and social relation improvement, or negative, according to music styles and messages, which may be associated to interferences in the treatment. Regarding the therapeutic potential, it was found that music helps to establish bonds and to develop personal and collective changes. As a conclusion, music promotes expression of emotions and perception of reality, and its use in the therapeutic context favors internal balance and exchange spaces.

KEYWORDS: Music; Mental Health; Mental Health Services; Drug Users.

O estudo apresentado é parte integrante do Grupo de Pesquisa em Saúde Mental e Saúde Coletiva da Universidade Estadual de Ciências da Saúde de Alagoas. Os dados fazem parte do Trabalho de Integração Curricular apresentado ao Curso de Terapia Ocupacional da Universidade Estadual de Ciências da Saúde de Alagoas, como requisito para obtenção do título de Bacharel em Terapia Ocupacional da primeira autora no ano de 2013.

1. Terapeuta Ocupacional. Residente Multiprofissional em Saúde Mental pela Universidade de Pernambuco (UPE). E-mail: nay_battista@hotmail.com

2. Terapeuta Ocupacional. Doutorado em Ciências pela Universidade de São Paulo (USP). Professora titular do Curso de Terapia Ocupacional da Universidade Estadual de Ciências da Saúde de Alagoas (UNCISAL). E-mail: maracrisribeiro@gmail.com

Endereço para correspondência: Universidade Estadual de Ciências da Saúde de Alagoas. Centro de Ciências da Saúde. Curso de Terapia Ocupacional. Rua Jorge de Lima, 113, Trapiche da Barra, CEP: 57010-382, Maceió/AL. Responsável pela Comunicação: Mara Cristina Ribeiro. Tel (82) 88280140. E-mail: maracrisribeiro@gmail.com 


\section{INTRODUÇÃO}

$\mathrm{O}$ processo de transformação do cuidado oferecido nos serviços de saúde mental de base comunitária, possibilitou a criação de iniciativas voltadas para a produção de vida, sociabilidade, arte, criatividade e transformação dos espaços de não convivência em espaços coletivos ${ }^{1}$.

Especificamente para o cuidado destinado a usuários de álcool e outras drogas, foram criados os Centros de Atenção Psicossocial para Álcool e Drogas (CAPSad), que visam o tratamento da dependência e uso abusivo com ênfase na reabilitação e reinserção social.

Esses serviços devem contar com o trabalho de equipe multiprofissional envolvida em propostas interdisciplinares com a finalidade de articular ações de redução de danos, prevenção, recuperação e inclusão².

Além do atendimento individual, são propostas atividades em grupos como oficinas terapêuticas, oficinas de geração de trabalho e renda, atividades lúdicas e desportivas, atendimento familiar, entre outras estratégias para estimular o protagonismo de seus usuários frente à vida $^{1}$.

Essas práticas compreendem uma série de atividades e dinâmicas variadas, que devem ser pensadas e discutidas por todos os atores que formam o serviço (gestor, profissionais da equipe técnica e demais profissionais de nível médio, usuários, familiares $\mathrm{e}$ comunidade adstrita) ${ }^{3}$.

Assim, elas são desenvolvidas na perspectiva da atenção psicossocial e devem estar articuladas com a melhoria da qualidade de vida, criação e fortalecimento de desejos, afetos, prazeres e vínculos tanto no interior dos serviços quanto no território em que os usuários desses serviços transitam.

Por ser a arte capaz de produzir subjetividades, catalisar afetos, engendrar territórios desconhecidos e/ ou inexplorados, ela vem sendo utilizada em suas várias expressões no contexto dos CAPSad, embora em alguns casos a apropriação do seu campo conceitual ainda ocorra de forma incipiente por parte de seus trabalhadores ${ }^{3}$.

À vista disso, ainda que haja indefinição por parte desses profissionais quanto às formas de compreensão da relação entre arte e terapia, o seu valor na reabilitação está na possibilidade de o usuário descobrir e ampliar suas potencialidades na conquista de espaços sociais ${ }^{3}$.

A música, como elemento do conjunto dessas expressões artísticas, também tem sido utilizada como instrumento no cuidado à pessoa em sofrimento mental no desenvolvimento de intervenções terapêuticas que possam promover a reabilitação e inclusão.

Nesse sentido, ela tem sido descrita como promotora do autoconhecimento, reflexão e estímulo ao convívio social ${ }^{4}$, sendo capaz de ampliar o protagonismo relacionado ao tratamento e às problemáticas do cotidiano.

Com o intuito de aprimorar o conhecimento sobre a potencialidade da música como recurso terapêutico, foi proposto pela disciplina de Terapia Ocupacional aplicada à Saúde Mental no período de graduação do curso de Terapia Ocupacional, o acompanhamento de um grupo de música oferecido em um CAPSad III.

Durante o desenvolvimento dessa experiência, surgiu a necessidade de um aprofundamento sobre a opinião dos usuários desse grupo com relação ao papel da música em suas vidas e no tratamento. Assim, com esse objetivo, foi desenvolvida uma investigação que buscou, a partir de seus resultados, refletir acerca do uso da música como ferramenta de intervenção no âmbito da saúde mental.

O presente artigo discorre sobre os resultados e as análises dessa pesquisa, que foi aprovada pelo Comitê de Ética em Pesquisa da Universidade Estadual de Ciências da Saúde de Alagoas em 09 de maio de 2013, sob o código $\mathrm{n}^{\mathrm{o}} 2007$.

\section{METODOLOGIA}

A investigação analítico-descritiva de abordagem qualitativa, desenvolveu estudo bibliográfico, observação e entrevistas semiestruturada com 10 usuários participantes do grupo de música de um CAPSad da cidade de Maceió, estado de Alagoas.

Foram definidos como critérios de inclusão dos sujeitos: participação no grupo de música há mais de um mês e aceite na colaboração com o estudo. Como critério de exclusão: impossibilidade de entender os propósitos da pesquisa.

No início da investigação foi realizada reunião com os participantes na qual todos foram esclarecidos sobre o desenvolvimento da pesquisa e convidados a participar conforme o desejo e disponibilidade de cada um.

A coleta de dados foi desenvolvida no período de junho a agosto de 2013. Os usuários que aceitaram participar foram orientados quanto aos riscos, benefícios, objetivos da pesquisa e assinaram o Termo de Consentimento Livre e Esclarecido.

As entrevistas foram gravadas e realizadas de forma individual em ambiente reservado, visando o sigilo 
dos entrevistados. Com duração média de 20 minutos, as questões foram norteadas por formulário semiestruturado elaborado pelas pesquisadoras e buscavam conhecer as preferências musicais e a relação da música na vida e no tratamento dos participantes.

Os dados coletados foram transcritos e analisados por meio da técnica de Análise Temática. Desta forma, todas as fases de análise foram desenvolvidas: pré-análise, exploração do material, o tratamento dos resultados, inferências e interpretações possíveis ${ }^{5}$.

\section{O GRUPO DE MÚSICA}

Proposto com fins terapêuticos, o grupo em que o estudo foi desenvolvido ocorria uma vez por semana, com uma média de 15 a 20 usuários participantes, era coordenado por uma psicopedagoga e contava com a participação de uma graduanda do curso de Terapia Ocupacional.

O material para o desenvolvimento do grupo baseava-se em letras de músicas e uso de violões.

A dinâmica utilizada pela coordenadora acontecia da seguinte forma: nos encontros, a profissional escolhia a temática a ser explorada pelo grupo e, a partir do tema, eram utilizadas canções para que os usuários pudessem interpretar suas letras; por meio de interações e diálogos, eram feitas articulações sobre a vida, o tratamento e sentimentos despertados; em outros momentos, a música era utilizada de forma mais livre e os usuários podiam tocar e cantar músicas a partir de suas próprias escolhas.

\section{RESULTADOS}

Com relação à caracterização dos participantes do estudo, verificou-se que a idade dos entrevistados variou entre 20 a 59 anos. Oito usuários eram do sexo masculino e dois do feminino. A maioria mencionou não ter nenhum tipo de laço conjugal, somente dois referiram ser casados. Dois concluíram o ensino fundamental e dois, o ensino médio, os demais afirmaram ter interrompido os estudos antes do término do ensino fundamental. Quatro nunca foram internados para o tratamento específico de uso de álcool ou drogas e seis referiram algum tipo de internação em instituições fechadas. A data de admissão no serviço variou do final do ano de 2009 a início de 2013.

No que diz respeito ao envolvimento dos entrevistados com a música no CAPS, seis participavam do grupo de música apenas cantando e quatro, além de cantarem, tocavam violão. A maior parte referiu ter iniciado o seu contato com a música dentro do CAPS por indicação da própria psicopedagoga que facilitava o grupo.

A partir da análise aprofundada dos discursos dos entrevistados, emergiram dois temas: Os impactos da música e a potencialidade terapêutica da música.

\section{Tema 1: Os Impactos da Música}

Ao serem indagados sobre os sentimentos que a música provocava, os entrevistados apresentaram as seguintes percepções:

[...]. Quando eu escuto essas músicas, sinto paz, alegria. Sempre que eu estou triste eu ouço música. [...] a música me faz bem, ela me transforma, me acalma, me alegra, é como se entrasse uma felicidade imensa, como se tirasse aquela coisa ruim que está aqui dentro. (U1)

[...]. Eu sinto o prazer de sentir a música, ela toca na alma, ela levanta a autoestima da pessoa. [...] ela faz a gente relaxar. (U10)

Além dos sentimentos positivos, foi evidenciada a capacidade que a música tem de resgatar memórias de relações sociais e momentos passados.

O forró eu me lembro do tempo de criança com os meus avós, música lenta de pessoas que eu me envolvi num relacionamento, o reggae me lembra quando eu saía com os amigos. (U2)

Eu tenho sentimento de libertação, começo a sonhar tudo de novo, em tudo que fui, os lugares que cheguei a tocar. (U9)

Os entrevistados também revelaram que as atividades realizadas com música são gratificantes, as falas evidenciam a satisfação ao participarem do grupo e indicam melhor vinculação ao tratamento:

Eu me sinto bem porque a gente vai cantar, vai partilhar sobre a música, eu sei que vou tocar, que as pessoas vão ouvir, [...] é um alivio, missão cumprida, mais um dia de tratamento. (U3)

A música também é percebida como facilitadora das trocas sociais sendo avaliada como um recurso positivo na ampliação do conhecimento cultural. 
[...] não tenho o dom para cantar, mas a música eu aprecio muito, porque somos brasileiros, e a nossa cultura é muito rica em termos de música [...]. A pessoa adquire mais conhecimento, porque a música é cultura. (U2)

Foi possível detectar que tipos diferentes de música podem provocar diferentes sentimentos.

Funk eu não curto, eu não gosto da letra, é muito vulgar. [...] Me dá revolta, angústia. (U1)

O que eu menos gosto é música com duplo sentido, música pornográfica e também esses estilos de Rap, mas o resto, as outras coisas eu gosto. (U7)

A percepção da música de forma negativa também foi apontada em relação a estilos musicais ou quando a letra da música traz mensagens que interferem negativamente no processo de tratamento.

A que eu menos gosto é a que fala de droga, reggae, eu saio até de perto [...] Eu sinto como se quisesse me levar pro mesmo lugar que eu estava. (U4)

\section{Tema 2: A Potencialidade Terapêutica da Música}

Ao serem questionados sobre possíveis mudanças na vida e no tratamento influenciados pela participação no grupo de música, as seguintes respostas foram obtidas:

Eu aprendi a ouvir mais meus companheiros, que não só sou eu que estou ali, [...] então é companheirismo poder ouvir os outros. (U3)

Eu fiquei mais popular, eu era mais reservado, estou aqui há quatro anos e de dois anos pra cá que eu vim me soltar mais. (U5)

Foi possível perceber que a música influencia diversos cenários e é considerada importante por contribuir nas mudanças pessoais e coletivas, colaborar nas trocas interpessoais e facilitar o trânsito nos ambientes.

Evidenciou-se o desejo de que a música estivesse presente em mais atividades no serviço, pois os entrevistados entendem essa abordagem terapêutica como uma necessidade.
Eu fico ansiosa, me faz falta quando não tem. [...] $\mathrm{Na}$ minha opinião deveria ter mais, até poder tocar um instrumento, montar um grupo. (U1)

[...] a gente quer mais, a gente quer um instrumento para cada um, a gente quer se afinar. (U9)

A partir da compreensão dessa necessidade, a música também foi descrita como ferramenta para transformações individuais e grupais no enfrentamento de situações difíceis do cotidiano, na melhora das condições de vida e do tratamento dos entrevistados.

Ontem eu [...] cheguei furiosa, me isolei e não quis mais conversa com ninguém, só pedi pra L. cantar pra mim. Foi o que me acalmou. (U1)

[...] eu tenho certeza, a música é o carro chefe pra você sair das drogas, pra você sair de qualquer vício que você tenha. (U9)

\section{DISCUSSÃO}

A pesquisa evidenciou que a música é capaz de resgatar sentimentos positivos, melhorar a autoestima, transformar realidades, proporcionar alegria, relaxamento e tranquilidade, promovendo assim, bem-estar. Isso indica que ela exerce funções que vão além da simples distração, tornando-se um meio de comunicação capaz de ultrapassar os limites da expressão verbal ${ }^{6}$.

Ela permite a associação com experiências significativas do passado, que evocam memórias específicas, em que é possível resgatar emoções, imaginação e experiências vividas? .

Desta forma, ao articular a música com as experiências de vida e do cotidiano, a dinâmica terapêutica utiliza a música como facilitadora no estimulo à memória. Assim, além de despertar sentimentos e vivências, seu uso pode possibilitar a ressignificação de lembranças.

Para Sekeff ${ }^{8}$, a música é um recurso de desenvolvimento pessoal, equilíbrio, estímulo e integração do indivíduo ao meio em que vive, capaz de favorecer o desenvolvimento de potencialidades além de associar e integrar experiências.

Bergold et al. ${ }^{9}$ consideram que ao utilizar a música em um grupo estimula-se a criatividade, o relaxamento e a diversão. Mesmo os que não têm habilidades musicais podem aprender a tocar instrumentos simples, a 
movimentação e a dança também podem ser estimuladas e facilitadas. Diante das possibilidades lúdicas, a música é capaz de favorecer a interação social.

Dentro dessa compreensão, a pesquisa também evidenciou que a participação em uma atividade grupal que gera emoções positivas ajuda na construção dos vínculos interpessoais.

O papel da música como intermediadora das relações que são desenvolvidas no setting terapêutico, facilita o estabelecimento de novos vínculos, por meio da conscientização de si e do outro dentro da perspectiva do coletivo.

Se considerarmos alguns aspectos da realidade dos sujeitos em tratamento nos CAPSad, tais como: muitos vínculos são rompidos em decorrência do processo de dependência de substâncias psicoativas como o álcool ou outras drogas, estes sujeitos apresentam sérias dificuldades em estabelecer novos vínculos e, a principal rede operante dentre os vínculos desses sujeitos é o $\mathrm{CAPS}^{10}$; pode-se afirmar que o grupo de música, inserido no contexto das atividades terapêuticas, tem sido reconhecido como um potencializador para o estabelecimento de novos vínculos e da manutenção deles, mostrando-se portanto, como componente que opera positivamente nesses processos vinculares.

Ao vivenciar a música, se estabelece uma relação com a rede de significados construídos no mundo social, a atividade musical enquanto integrante de uma cultura é vivida na dimensão coletiva, que pode receber significações que são compartilhadas socialmente ${ }^{11}$.

Quando utilizada com fins terapêuticos nos CAPS, a música permite compartilhar problemas, interagir com o outro ao dar apoio e auxílio no processo de solução das dificuldades vivenciadas. Além de mediar relações, também cumpre outros objetivos como a ampliação de conhecimentos e potencialidades pessoais e desenvolvimento de práticas voltadas às questões sociais $\mathrm{e}$ culturais locais.

Embora seja possível elencar uma gama de benefícios trazidos pela música, é importante perceber o contexto social e cultural ao qual o indivíduo está inserido, pois é preciso apontar que as atividades com música também podem trazer sentimentos negativos.

Uma seleção de músicas inapropriadas pode atuar como um fator estressante ${ }^{9}$, além disso, os sentimentos e as reações despertadas pela música não são iguais para todas as pessoas. Portanto, é difícil generalizar a comunicação e a significação musical, este processo é dialético e acontece inserido na dimensão cultural, por meio da ação dos sujeitos ${ }^{11}$.
Por isso deve-se levar em consideração a relação de cada sujeito com a música, sendo difícil propor uma regra geral. A música reporta a singularidade de cada pessoa, suas vivências pessoais, familiares e culturais, e, portanto, poderá interferir de forma positiva ou negativa de acordo com cada experiência vivida ${ }^{6}$.

Por favorecer o despertar da afetividade e contribuir para a forma como o sujeito percebe o mundo que o cerca ${ }^{12}$, a música pode ser capaz de remover barreiras, minimizar resistências, melhorar a comunicação, a relação com o usuário e ainda facilitar o acesso ao tratamento ${ }^{13}$.

Os usuários, ao participarem do grupo, apontam a música como necessidade, afirmam o interesse em mais atividades com música no CAPS, demonstram o desejo de aprender a tocar instrumentos, montar grupos de música para apresentações dentro do serviço ou mesmo em outros espaços. Entende-se que o contato com a música proporciona conquistas que levam ao reconhecimento da realidade e apropriação de si mesmo, dessa forma, os usuários demonstram interesse em transformar a realidade em que se inserem.

Além disso, atividades realizadas com música podem provocar reações físicas que possibilitam mudanças e transformações, levando os sujeitos a operarem novas realidades que intensificam suas vidas ${ }^{14}$. Como integrante da arte, a música possui a capacidade de favorecer a expressão de sentimentos, emoções, sensações, percepções e, consequentemente, organizar conteúdos internos ${ }^{15}$.

A música, em um contexto grupal e utilizada com fins de apoiar estratégias de cuidado do CAPS, é descrita como ferramenta facilitadora de transformações individuais e grupais no enfrentamento de situações difíceis do cotidiano e na melhora das condições de vida.

Os CAPS devem eleger intervenções que possam estabelecer vínculos que se fortaleçam cotidianamente ${ }^{16}$, que ofereçam espaços de acolhimento de diferentes necessidades do sujeito em sofrimento mental e que possam dar respostas efetivas a essas necessidades, contribuindo para o estabelecimento do vínculo com a instituição e com o tratamento.

Nesse sentido, a música, como evidenciado no estudo, colabora nessa constituição vincular e, por meio dela, o serviço poderá desenvolver a inserção não apenas dentro do serviço, mas também fora dele.

Portanto, enquanto recurso de intervenção no CAPSad, a música se mostra como um componente significativo, potencializador de mudanças individuais e coletivas e, por isso, deve estar mais presente nas ações terapêuticas voltadas para a reabilitação e inclusão. 


\section{CONCLUSÃOO}

O principal objetivo desse estudo consistiu em compreender o papel da música na vida e no tratamento de usuários de um CAPSad e, a partir dos resultados, refletir sobre o seu uso como ferramenta de intervenção.

Evidenciou-se que a música promove a ressignificação de lembranças, expressão de emoções e percepção da realidade e a sua utilização no contexto terapêutico favorece o equilíbrio interno e facilita espaços de trocas nos grupos, na cultura e nos territórios onde se transita ou se quer transitar.

\section{REFERÊNCIAS}

1. Ribeiro MC. Os Centros de Atenção Psicossocial como espaços promotores de vida: relatos da desinstitucionalização em Alagoas. Rev Ter Ocup Univ São Paulo. 2013:24(3):174-82. DOI: http:// dx.doi.org/10.11606/issn.2238-6149.v24i3p174-182 .

2. Brasil. Ministério da Saúde. Secretaria Executiva. Coordenação Nacional de DST/AIDS. A Política do Ministério da Saúde para atenção integral a usuários de álcool e outras drogas / Ministério da Saúde, Secretaria Executiva, Coordenação Nacional de DST e AIDS. - Brasília: Ministério da Saúde, 2003.

3. Azevedo DM, Miranda FAN. Oficinas terapêuticas como instrumentos para recuperação. Esc Anna Nery. 2011;15(2):339-45. DOI: http://dx.doi.org/10.1590/S141481452011000200017 .

4. Tavares CMM. O papel da arte nos centros de atenção psicossocial - CAPS. Rev Bras Enferm. 2003;56(1):35-9. DOI: http://dx.doi.org/10.1590/S0034-71672003000100007.

5. Bardin L. Análise de conteúdo. São Paulo: Edições 70; 2011.

6. Seki NH, Galheigo SM. O uso da música nos cuidados paliativos: humanizando o cuidado e facilitando o adeus. Interface. Comunic Saude Educ. 2010;14(33):273-84. DOI: http://dx.doi.org/10.1590/S1414-32832010000200004 .

7. Antelo M. Psicanálise e música. Cógito, Salvador. 2008;1(9):91-3.

8. Sekeff ML. Da música, seus usos e recursos. São Paulo: UNESP, 2007.

9. Bergold LB, Alvim NAT, Cabral IE. O lugar da música no espaço do cuidado terapêutico: sensibilizando enfermeiros com a dinâmica musical. Texto Contexto Enferm.

Received: 04.10.15

Accepted: 07.07.16
Nesse sentido, a experiência relatada indica que os serviços e os profissionais envolvidos no cuidado em saúde mental, devem considerar o uso da música em novas proposições terapêuticas, ampliando suas potencialidades transformadoras que operam no indivíduo, no coletivo e, sobretudo, no fortalecimento dos vínculos que são tão comprometidos na trajetória de dependências às drogas.

Por fim, é preciso apontar que o estudo se referente a apenas um serviço, portanto, destaca-se a necessidade de estudos mais abrangentes relacionados ao uso da música como recurso terapêutico em serviços de atenção à saúde mental.

2006;15(2):262-9. DOI: http://dx.doi.org/10.1590/S010407072006000200010 .

10. Souza J, Kantorski LP. A rede social de indivíduos sob tratamento em um CAPS ad: o ecomapa como recurso. Rev Escola Enferm USP. 2009;43(2):373-83. DOI: https:// dx.doi.org/10.1590/S0080-62342009000200017

11. Wazlawick P, Camargo DD, Maheirie K. Significados e sentidos da música: uma breve "composição" a partir da psicologia histórico-cultural. Psicol Estud. Maringá. 2007;12(1):105-13. DOI: http://dx.doi.org/10.1590/S141373722007000100013 .

12. Maheirie K. Processo de criação no fazer musical: uma objetivação da subjetividade, a partir dos trabalhos de Sartre e Vygotsky. Psicol Estud. Maringá. 2003;8(2):147-53. DOI: http://dx.doi.org/10.1590/S1413-73722003000200016 .

13. Marques Filho AB, Coelho CLS, Ávila LA. A música removendo barreiras e minimizando resistências de usuários de substâncias. Rev SPAGESP- Soc Psicoter Analíticas Grupais do Estado de São Paulo. 2007;8(1):14-24.

14. Almeida MVM. Terapia Ocupacional de corpo inteiro: uma introdução. In: Almeida MVM. Corpo e Arte em Terapia Ocupacional. Rio de Janeiro, RJ: Enelivros; 2004. p. 1-6.

15. Lima FP, Oliveira ML, Wilrich JQ. Relato de experiência - a arte como instrumento de reinserção social. J Nurs Health, Pelotas. 2012;2(1):266-75.

16. Ferrari SML. Terapia Ocupacional: a clínica numa instituição de saúde mental. Cad Ter Ocup UFSCar. 2006;14(2):121-7. Disponível em: http://www.cadernosdeto.ufscar.br/index.php/ cadernos/article/view/161/117 . Acesso em: 12 jan.2015. 